of asbestosis were eleven per cent more common than in controls taken from other shipyard workers.

The disturbing feature of this report is that the pipe coverers were working in an environment where the exposure to asbestos dust was at about the recommended maximum level thought to be safe. This research is described in the New England Journal of Medicine by a group from the Harvard School of Public Health and the Boston medical school $(\mathbf{2 8 5}, 1271 ; 1971)$, and is an invaluable account of the condition of workers in an asbestos environment that is known from long term studies to have been more or less constant for twenty years.

There is no specific diagnostic test for asbestosis so that the diagnosis depends on the presence of symptoms such as shortness of breath on exercise, X-rays of the lungs, tests of respiratory function and clinical findings, particularly auscultation of the lungs for the character of the breath sounds and the occurrence of abnormal sounds. Other dust-induced lung diseases lead to similar signs and symptoms; the final diagnosis depends on a history of exposure to asbestos.

In the present investigation, the exposure to asbestos was not in doubt. What the investigators wished to discover was the extent to which the workers in an environment thought to be safe showed respiratory disorders attributable to asbestosis. To minimize the subjective elements the $\mathrm{X}$-rays were examined independently by three radiologists, and criteria were established for the diagnosis of asbestosis based on the presence of a number of clinical abnormalities.

The control group was matched for age, duration of employment, height and weight, smoking habits, marital status, and location of residence. The pipe coverers had been employed in the shipyard for an average 17.4 years and the controls 17.1 years.

The striking result of the survey is that of 101 pipe coverers (compared with 94 controls), thirty-eight per cent of workers with twenty years of cumulative exposure had asbestosis.

Although slow in onset-asbestosis was never diagnosed in men with less thar: ten years' cumulative exposure -asbestosis progresses to a severely disabling and ultimately fatal disease impairing the function of the lung. Small fibres, when inhaled, can penetrate the tissue of the lungs causing reactions which lead to destruction of normal lung tissue. Apart from being itself a lethal disease, asbestosis lowers the resistance to pulmonary tuberculosis and increases the liability to cancer of the lung.

This painstaking survey of the shipyard will no doubt play an important part in the establishment of threshold limits for exposure to asbestos dust, and as the New England Journal of Medicine says in an editorial, the threshold limit value should be lowered far below some recent proposals.

\section{DNA REPLICATION \\ BNA Pilmer}

from our Cell Biology Correspondent

A LITTLE may be known about the biochemistry of the semi-conservative replication of DNA but, as a glance through the contents tables of the current batch of journals shows, that is not for want of trying. Brutlag, Schekman and Kornberg (senior), for example, report (Proc. US Nat. Acad. Sci., 68, 2826; 1971) an intriguing set of observations which they believe indicates that RNA polymerase is involved in the initiation of replication of single standard, circular M13 DNA; they suggest that the RNA polymerase may act by providing an RNA primer molecule onto the $3^{\prime}$ hydroxy group of which DNA polymerase initiates DNA synthesis.

Brutlag et al.'s observation is simply that the conversion of single stranded M13 DNA to a double stranded replicative form and the subsequent replication of the replicative form in Escherichia coli is blocked by rifampicin, a specific inhibitor of $E$. coli RNA polymerase. Furthermore, as expected from this observation, this block to replication of M13 DNA is not seen when $E$. coli cells, which have an RNA polymerase mutated to resistance to rifampicin, are infected in the presence of the drug.

Not so long ago the suggestion that an RNA chain might prime DNA polymerization would certainly have been viewed askance, but now that Baltimore's group (Verma et al., Nature New Biology, 233, 131; 1971) have shown that reverse transcriptase initiates DNA synthesis, directed by an RNA template, on an RNA primer such a suggestion is unlikely to cause any great stir. Indeed, Verma et al. themselves suggested that DNA polymerases like reverse transcriptase might initiate DNA synthesis with an RNA primer.

In the same issue of the Proceedings (ibid., 2839) Inselburg and Fuke report that minicells produced by the mutant strain of $E$. coli, P678-54, which carries the colicin $\mathrm{E} 1$ genome, contain colicin E1 DNA but no cellular DNA. The circular colicin E1 genomes in these minicells seem to continue to replicate and various catenated and replicating E1 DNA molecules can be extracted. According to Inselburg and Fuke the behaviour of these colicin DNA molecules when sedimented in sucrose and caesium chloride-ethidium bromide density gradients indicates that both Cairnstype double forked circular molecules and Rolling circle-type circular molecules with linear tails are present.

Elsewhere, Strätling and Knippers ( $J$. Mol. Biol., 61, 471; 1971) relate their latest observations of DNA synthesized by DNA-membrane complexes isolated from polA- mutant $E$. coli cells. These cells lack DNA polymerase I (Kornberg enzyme) activity but have at least one

\title{
Location of Calcium lons in Striated Muscle
}

STUDies on the structure of muscle filaments have gradually made clear a general framework for hypotheses on the mechanism of muscle contraction. The basic force-developing step is still elusive, however, and there are also several features about the "switching on" process about which very little is certain. It is useful therefore to have any new information on these events, and a report by Yarom and Meiri of the Hebrew University, Jerusalem, in next Wednesday's Nature New Biology describes some experiments designed to fix the location of the chief storage site for calcium ions.

Potassium pyroantimonate has previously been shown to precipitate calcium in cardiac muscle, and Yarem and Meiri used this method to precipitate and thus locate the calcium ions in striated muscle. The muscle was treated with a solution of sucrose, potassium pyroantimonate and the fixative osmium tetroxide at $p \mathbf{H}$ 7.2. Electron micro- graphs of longitudinal sections of these muscles showed stain between the myofilaments and it concentrated in particular along a line in the I band known as the $\mathrm{N}_{2}$ line. The two $\mathrm{N}$ lines are densely staining lines in the $\mathbf{I}$ band and the $\mathrm{N}_{2}$ line differs from the $\mathrm{N}_{1}$ in that the distance of the $\mathrm{N}_{2}$ line from the $\mathrm{Z}$ lines increases with sarcomere length. The muscles were then tetanized electrically through the nerve and fixed during the tetanus plateau. Longitudinal sections from such muscles did not show predominantly stained $\mathrm{N}_{2}$ lines, but the stain was dispersed along the myofilaments. Additional muscles were treated with EGTA, a strong calcium chelating agent, and were then treated with pyroantimonate and the osmium tetroxide fixative. No myofibrillar deposits were observed in longitudinal sections of these muscles.

Thus, Yarom and Meiri suggest, it is possible that the $\mathrm{N}_{2}$ lines are sites for the storage of intracellular calcium. 